\title{
How Much, How Often?
}

In a detailed analysis of the reserve book collection at the University of Alberta, it was found that students made more extensive use of material assigned frequently in small amounts than when all of the material was assigned on only one occasion. Students utilized 92 percent of the former material compared with only 57 percent of the latter. Action that may be taken to reduce the cost of reserve systems is discussed.

\section{INTRODUCTION}

$M$ ANY DETAILED STUDIES of reserve book circulation systems agree with Downs, who, in 1967, wrote:

Students, librarians and many faculty members are in agreement that the reserve book plan is unsatisfactory. . . . Some of the most common abuses of the reserve book system, e.g., placing too many books on reserve, keeping books on reserve when they are infrequently called for, and seldom revising reserve lists can be eliminated by close cooperation between faculty and library staff members who are in charge of the reserve collection. ${ }^{1}$

Closer cooperation between the library staff and teaching faculty is often implied though rarely stated in studies of reserve book systems. ${ }^{2}$ Feedback from librarians to the faculty is the only means of indicating the actual use of reserve items. Feedback infers that faculty should either remove little-used material from their reserve lists, or, if the books are considered essential reading, stimulate increased student use. The recent study of Carmack and Loe-

At the time of writing, Peter Marshall was information officer with Alberta Research, Edmonton, Alberta. He presently is with Information Services, Calgary, Alberta. ber indicates that feedback can reduce material having low circulation and thereby lower the cost per item on reserve. ${ }^{3}$

Carmack and Loeber suggest that individual instructors may have to reevaluate their teaching methods in order to stimulate the use or justify the additional cost of material being placed on reserve. Unfortunately, the authors failed to look for any correlation between teaching methods and usage of reserve material. It was impossible, therefore, to make any suggestions as to how the faculty could assist librarians in making reserve collections more economical. After all, the cost of reserve systems is borne by the library; hence, librarians must consider every means of improving service and lowering costs.

The aim of this study is to compare two methods of presenting reading lists, with their associated use of material. The first method is the traditional, long reading list handed out at the beginning of the term. Infrequently, items on the reading list are mentioned in lectures with the hope that students will be reminded of their assignments. The second method involves multiple reading lists. The readings are assigned at frequent intervals, but in small amounts. Because of the continual reminders and seemingly smaller work load, a higher 
use factor is generated by this method.

The study was conducted in the Reserve Reading Room of the library at the University of Alberta, Edmonton, Alberta. The university has a total student body of 18,500 and a faculty of 1,300 . Library collections total $1,000,000$ volumes. Separate libraries on campus serve education, law, and medicine; the Reserve Reading Room is used primarily by students in arts and sciences (approximately 6,000$)$. At the time the study was conducted (spring 1972), 430 of the 450 faculty in arts and sciences placed books on reserve, and the reserve collection totaled some 17,200 titles. The study involved a selection of eight classes, four where faculty placed only one large list of books on reserve and four where faculty employed multiple lists. The classes were of similar size (thirty to forty students, with a mean of thirty-six) and were evenly distributed across the various disciplines of arts and sciences.

\section{THE STUdY}

The basis of comparing the two methods is the number of potential user items of each group. This figure is obtained by the multiplication of the number of potential users-the class size-with the number of items on re- serve for that course. Thus, if each student read each article once, then the actual use of the system would correspond with the potential user items calculated for that class. A lesser figure than the potential user items indicates that the system is not completely fulfilling its intended function. Few systems do. There is a marked difference, however, in the use of a reserve system by different groups of students.

Because of the different numbers of items on reserve for each course and the unequal number of students in each course, the data have been reduced to percentages so that accurate and ready comparison may be made. Table 1 shows the number of potential user items and the percentage of actual items signed out. In order to arrive at a clearer level of the number of users, the percentage of duplicate signatures has also been presented. In both cases it is almost the same.

The difference in actual use between the method which entails one lengthy reading list of reserve materials given out at the beginning of the term, the group one data, and the use of frequent short assignments, as illustrated by group two data, is quite marked. While it is true that these figures are totals and that each method will have ex-

TABLE 1

User Data for Lengthy Single Lists and Short Multiple Reserve Book Lists

\begin{tabular}{lcc}
\hline \multicolumn{1}{c}{ Category } & Lengthy Single Lists & Short Multiple Lists \\
\hline Number of potential user items & $100 \%$ & $100 \%$ \\
Number of user items signed out & $57 \%$ & $92 \%$ \\
Number of user items with duplicate signatures & $8 \%$ & $6 \%$ \\
Number of user items without duplicate signatures & $49 \%$ & $86 \%$ \\
Average number of duplicates of each item available & 5.3 & 9.9 \\
Maximum number of duplicates used in twenty-four hours & 11.0 & 16.0 \\
Maximum number of duplicates used at one time & 4.0 & 5.0 \\
Useful (class size $\pm 33 \%$ of class size, i.e., $66 \%$ to $133 \%$ of users) & & \\
items & $38 \%$ & $77 \%$ \\
Highly used ( $>133 \%$ of users) items & $4 \%$ & $4 \%$ \\
Little used ( $>10 \%$ but $<66 \%$ of users) items & $33 \%$ & $19 \%$ \\
Very little used (<10\% of users) items & $25 \%$ & $0 \%$ \\
\hline
\end{tabular}


amples of both poorly and heavily used items, it is apparent that one system is far more effective in making use of reserve materials than the other.

A breakdown of the use of individual items indicates whether particular material receives emphasis or whether all of the material is being used to some extent. The reason for detailed analysis is that possibly some material receiving little use should be returned to the open-shelf collection where it might attract an equally large number of readers as when it is on reserve.

For the purpose of this study, "useful items" are defined as those whose use equalled the class size plus or minus one-third of the class size, i.e., 66 percent to 133 percent of the potential number of users. This material is considered by both faculty and students to be important for the particular course.

"Highly used" material consists of those items used by more than 133 percent of the potential number of users, while "little used" refers to material used by more than 10 percent but less than 66 percent of the potential number of users. "Very little used" items are defined as those items borrowed by less than 10 percent of the potential number of users.

Because of the problem of deciding the dividing line between what should and what should not go on reserve, the categories, though arbitrarily determined, appear to reflect actual patterns of use. It has been found that the data cluster within these limits rather than being dispersed across the boundaries. For the purpose of analyzing the given data, the categories as defined are adequate.

The table shows the marked difference between the two groups of data. The increase in the material in group two, that announced frequently but in small amounts, derives mostly from the absence of very little used items. In fact, virtually all of the material put on reserve was used by more than 33 percent of the potential users. This contrasts with almost half of the group one material being used by fewer than 50 percent of the users.

\section{Discussion}

The reasons for the marked difference in the use of reserve material are diverse and at times difficult to assess. The most apparent reason might be the availability of material as indicated by the number of copies of each item on reserve. As indicated in the table, group one has an average of 5.3 duplicate copies per item on reserve. On the other hand, group two has 9.9 duplicate copies available at all times.

When one searches the checkout data, it becomes apparent that the difference in the number of copies available is not an important reason for the different levels of material use. The maximum daily use per item was eleven and sixteen checkouts per course for groups one and two respectively. The maximum use at any one time, usually for overnight loans, was four and five copies respectively. Thus, having five copies of each item satisfied virtually all demand without incurring the tremendous surplus and associated costs of maintaining some ten duplicate copies per item on reserve.

A less apparent, but possibly more significant finding is that the group one use was concentrated just prior to either the mid-term or the end-of-term examinations. In fact, the end-of-term checkouts reached a maximum during the examination week. On the other hand, when short but frequent lists were assigned, use was dispersed quite evenly over weekly periods as well as over the whole term. A slight increase was noted toward the end of the term and examinations. These contrasting modes of use suggest that, in the former 
group, reserve material does not play a part in the day to day study of the students. Rather, students see it only as a last minute task. Given the relatively low circulation figures in the table, it is apparent that few students even bother to use most of the material at all. Only those items given preference in the lectures are well used. The remaining 58 percent of the material might not have been placed on reserve. In this case, a considerable portion of the cost of the reserve material is unjustified.

\section{SUMMARY}

In short, to be effective, a reserve system must have a consistently high rate of circulation. The tentative conclusion reached, as a result of the study, is that there is a rather substantial gap between different teaching methods as reflected in the use of reserve material. In light of this finding, the teaching faculty and the librarians together must take a critical look at the present reserve system. It is not sufficient for librarians to simply forward the total, or even circulation figures of individual items, to the faculty at the end of each term. What must accompany the figures is a basis on which the faculty can judge the effectiveness of the material they choose, and more important, how the material is brought to the attention of the students.
At that time some guidelines as to the usefulness of reserve material must be established. Material that is very little used should be removed from the reserve system immediately. Items in the "little used" category might remain on reserve for a second term. If, however, circulation of these items does not improve in the second term, they too might be removed. What remains is that material which most students find useful to their studies. The crux is that if the faculty wish to have numerous items on reserve, available to all of the students, then they must see to it that their method of teaching entices the students to make use of those items.

While some faculty may resent any limitations or guidelines on the number of items, or especially on particular items that can be put on reserve, it is obvious to the cost-conscious librarian that without some form of weeding, material not suited to the reserve system will soon choke the service, reduce the overall effectiveness, and raise costs. Close cooperation between the librarian and faculty must be achieved. Along with an encouraging rise in the use of the reserve material, it should become apparent to the faculty that more careful selection of material placed on reserve, according to the guidelines, results in more effective teaching and lower cost per item on reserve.

\section{REFERENCES}

1. Robert B. Downs, Resources of Canadian Academic and Research Libraries (Ottawa, Ontario: Association of Universities and Colleges of Canada, 1967), p.84.

2. Roger P. Bristol, "Simple Reserve System," Special Libraries 60:659-60 (Dec. 1969); Bob Carmack and Trudi Loeber, "The Library Reserve System-Another Look," College \& Research Libraries 32:105-9 (March 1971); Mary Jane Gibson, "Letters to the
Editor," College \& Research Libraries 32: 228 (May 1971); Frank A. Lundy, "Slow Moving Reserve Books," Library Journal 94: 4076 (Nov. 15, 1969); Peter Simmons, "Reserve Collections: Some Computer Assistance for the Perennial Problems," Canadian Library Journal 29:82-87 (March-April 1972).

3. Carmack and Loeber, "The Library Reserve System." 